\title{
THERMAL CONDUCTIVITY AND VISCOSITY OF WATER AND ETHYLENE GLYCOL BLEND BASED ALUMINA NANOFLUIDS - AN EXPERIMENTAL STUDY
}

\author{
RAVI BABU. $\mathrm{S}^{1}$ \& SAMBASIVA RAO. $\mathrm{G}^{2}$ \\ ${ }^{I}$ Department of Power Engineering, GMR Institute of Technology, Rajam, Andhra Pradesh, India \& \\ Research Scholar, Acharya Nagarjuna University, Guntur, Andhra Pradesh, India \\ ${ }^{2}$ Sir.C. R. Reddy College of Engineering, Eluru, Andhra Pradesh, India
}

Water and Ethylene Glycol (EG) blend is a kind of conventional heat transfer fluid, generally used in many energy systems, to retain the good heat transfer (heating or cooling) ability of water, as well as widening the operating temperature range. Further, the enhancement of thermo-physical properties of water/EG blend, by using nanoparticles would be very useful for the better performance of the energy systems. In the present study, alumina particles are used to prepare and determine the thermal conductivity and viscosity of Water and Ethylene Glycol (EG) blend based alumina nanofluid. It is observed that, the maximum augmentation occurs in the thermal conductivity is $11.37 \%$ at 1.6 Vol\%, for water+EG based $\mathrm{Al}_{2} \mathrm{O}_{3}$ nanofluids. It is also observed that, dynamic viscosity is increased by $10.36 \%$ by 1.6 Vol\%, for $($ Water $+\mathrm{EG}) / \mathrm{Al}_{2} \mathrm{O}_{3}$ nanofluid compared to water $+\mathrm{EG}$ blend. Thermal conductivity and viscosity models for water $+\mathrm{EG}$ based $\mathrm{Al}_{2} \mathrm{O}_{3}$ nanofluid, are proposed.
\end{abstract}

KEYWORDS: Heat Transfer, Nanofluids, Thermal Conductivity, Viscosity \& Ethylene Glycol

Received: Aug 08, 2017; Accepted: Aug 28, 2017; Published: Sep 15, 2017; Paper Id.: IJMPERDOCT201719

\section{INTRODUCTION}

In recent years, the development of nanotechnology, enables to emerge a new class of heat transfer fluid, which is a colloidal dispersion of nanoparticles $(<100 \mathrm{~nm}$ size $)$ and base fluids, called nanofluid. The main reason to focus on nanofluid is its superior thermo physical property improvement, especially thermal conductivity and it further leads to improve the heat transfer capability of the base fluid. This characteristic improvement ensures the nanofluid application, in different areas such as electronic cooling, solar energy systems, automobile engine cooling, heating and cooling of buildings, etc. Generally, water and Ethylene Glycol (EG) is used as heat transfer fluids, among the other liquids. But, water cannot be used at very high or lower temperatures, due to its low boiling and freezing points, eventhough, it is having high thermal conductivity, compared to EG. So, water and Ethylene Glycol blend is always used as a commercial heat transfer fluid, in different heat transfer applications, for wider temperature range. In this study, water and EG is used as carrier fluid, and alumina nanoparticles are used for synthesizing the nanofluids in different volume concentrations, for improving thermo physical properties. It is very much necessary to know the thermo physical properties of nanofluids, before it is used for heat transfer applications. Maxwell [1], proposed a model for determining the thermal conductivity, for the liquid blend having nanoparticles. Wasp [2], proposed a model for thermal conductivity of solid-liquid slurry. Ravikanth et.al [3], experimentally determined the thermal conductivity for three types of nanofluids, and proposed a new correlation which is a function of temperature and nanoparticle volume fraction. Abdolbaqi et.al [4], experimentally 
investigated the thermal conductivity and viscosity of BioGlycol/water based $\mathrm{SiO}_{2}$ nanofluids, and developed new correlations. Syamsundar et.al [5], conducted an experimental study, to measure thermal conductivity and viscosity of water based nanodiamond (ND), nanofluids and proposed correlations. Table.1, shows the correlations proposed for thermal conductivity by the researchers.

Table 1: Thermal Conductivity Models Proposed in the Literature

\begin{tabular}{|l|l|}
\hline \multicolumn{1}{|c|}{ Researcher Group } & \multicolumn{1}{c|}{ Proposed Correlations/Models } \\
\hline Maxwell [1] & $k_{n f}=\frac{k_{p}+2 k_{b f}+2\left(k_{p}-k_{b f}\right) \phi}{k_{p}+2 k_{b f}-\left(k_{p}-k_{b f}\right) \phi} k_{b f}$ \\
\hline Wasp model [2] & $k_{n f}=\frac{k_{p}+2 k_{b f}-2\left(k_{b f}-k_{p}\right) \phi}{k_{p}+2 k_{b f}+\left(k_{b f}-k_{p}\right) \phi} k_{b f}$ \\
\hline Ravikanth S. et.al [3] & $\begin{array}{l}k_{n f}=\frac{k_{p}+2 k_{b f}-2\left(k_{b f}-k_{p}\right) \phi}{k_{p}+2 k_{b f}+2\left(k_{b f}-k_{p}\right) \phi} k_{b f}+5 \times 10^{4} \beta \phi \rho_{b f} C_{p b f} \sqrt{\frac{\kappa T}{\rho_{p} d_{p}} f(T, \phi)} \\
f(T, \phi)=\left(2.8217 \times 10^{-2} \phi+3.917 \times 10^{-3}\right)\left(\frac{T}{T_{0}}\right)+\left(-3.0669 \times 10^{-2} \phi-3.917 \times 10^{-3}\right)\end{array}$ \\
\hline Abdolbaqi et al [4] & $k_{n f}=k_{b f} \times 1.199\left(\frac{\phi}{100}\right)^{0.03} \times\left(\frac{T}{100}\right)^{0.008}$ \\
\hline Syam Sunder et.al [5] & $k_{n f}=k_{b f} \times 1.041\left[(1+\phi)^{0.22}\left(\frac{T_{\min }}{T_{\max }}\right)^{0.0539}\right]$ \\
& $0.0 \%<\Phi<1.0 \%, \mathrm{~T}_{\min }=293 \mathrm{~K}, \mathrm{~T}_{\max }=333 \mathrm{~K}$ \\
\hline
\end{tabular}

Table 2: Viscosity Models Proposed in the Literature

\begin{tabular}{|l|l|}
\hline \multicolumn{1}{|c|}{ Researcher Group } & Proposed Correlations/Models \\
\hline Brinkman [6] & $\mu_{n f}=\mu_{b f}(1-\phi)^{-2.5}$ \\
\hline Gherasim [7] & $\mu_{n f}=0.904 \mu_{b f} e^{14.8 \phi}$ \\
\hline Brownian [8] & $\mu_{n f}=\mu_{b f}\left(1+2.5 \phi+6.17 \phi^{2}\right)$ \\
\hline Nguyen [9] & $\mu_{n f}=\mu_{b f}\left(1+0.025 \phi+0.015 \phi^{2}\right)$ \\
\hline Maiga [10] & $\mu_{n f}=\mu_{b f}\left(1+7.3 \phi+123 \phi^{2}\right)$ \\
\hline Einsten [11] & $\mu_{n f}=\mu_{b f}(1+2.5 \phi)$ \\
\hline Pak and cho [12] & $\mu_{n f}=\mu_{b f}\left(1+39.11 \phi+533.9 \phi^{2}\right)$ \\
\hline
\end{tabular}

Brinkman [6], proposed the correlation for dynamic viscosity of concentrated suspensions and solutions. Gherasim [7], did an experimental investigation of nanofluids, in confined laminar radial flows and also measured viscosities proposed correlation. The hydrodynamic behavior of the suspension of polar particles, is experimentally observed by Orozco [8]. Nguyen et.al [9], synthesized and determined the Viscosity data for $\mathrm{Al}_{2} \mathrm{O}_{3^{-}}$water nanofluid, and proposed the model using regression correlation. Maiga et.al [10], Einsten [11], Pak and Cho [12], also proposed the correlations for viscosity. The models for viscosity, proposed by various researchers in the literature are shown in Table 2 .

\section{SYNTHESIS AND CHARACTERIZATION}

In this study, nanofluid is synthesized using the two step method. Water, EG are taken in $3: 1$ ratio and mixed directly, to prepare the carrier fluid. Two step method, preparation of nanoparticles is to be done initially, and mixing them with the base fluid will be done later. $\alpha-\mathrm{Al}_{2} \mathrm{O}_{3}$ nanoparticles (99.5\% purity), were purchased from Nano Labs, India. The purchased alumina particles are having an average size of 30-50nm. Alumina nanoparticles are dispersed into the DM water, and the EG blend in the required quantity, to obtain the desired volume fraction of nanofluid, and stirring is done in 1 hour, using a magnetic stirrer. The amount of the nanoparticles to be added, making the nanofluid can be calculated, using the following relation (1). 
After magnetic stirring is done, a surfactant (sodium dodecyl sulfate (SDS)) of $0.01 \mathrm{Vol} \%$ is added to the nanofluid. The nanofluid is then sonicated, using an Ultrasonic sonicator (Oscar Electronics Make), at $20 \mathrm{KHz}$ frequency, for span of 3 hours to break agglomerations occurred, and gets the stable suspension. XRD analysis of alumina nanoparticles, is shown in Figure 1.

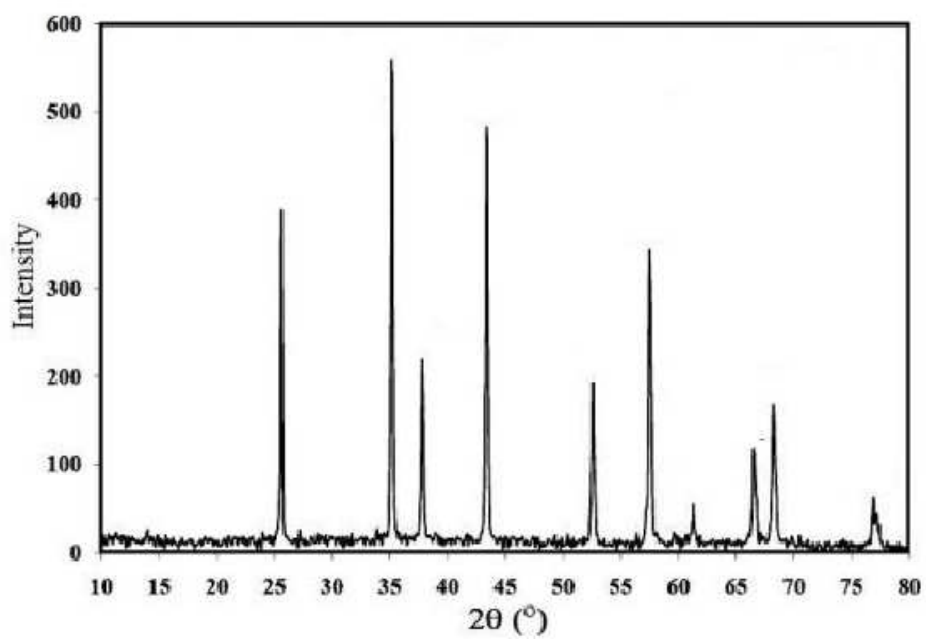

Figure 1: XRD Analysis of $\mathrm{Al}_{2} \mathrm{O}_{3}$ Nano Particles [14]

\section{EXPERIMENTS}

TAGUCHI method is one of the best tools, for designing a system in the systematic approach, to find out the optimal settings of parameter to produce results with minimum variation. This method helps to carry out a limited number of experiments, to achieve accurate results. The method is good to adapt, when the parameters were qualitative and discrete in nature. Experiments are planned to conduct, according to the L25 orthogonal array of various combinations of process parameters, volume fraction and temperature at various levels (1-5), given by TAGUCHI design of experiments, using MINITAB Software.

\section{MESAUREMENT OF THERMAL CONDUCTIVITY}

In the present study, A KD2-Pro analyzer (Decagon Devices Inc., USA) was used to measure the thermal conductivity of water / EG mixtures based, alumina nanofluids. This instrument is popularly used for thermal conductivity measurements and it works on transient hot wire method. It has $60 \mathrm{~mm}$ long and $1.3 \mathrm{~mm}$ diameter, KS-1 which served both as a temperature sensor and line heat source. Test sample was placed in a constant temperature water bath vertically, and the probe was completely immersed in the nanofluids. The vessel and probe were maintained at the required temperature, for $15 \mathrm{~min}$ to reach steady state before each measurement, to get accurate results. This instrument was calibrated with the known thermal conductivity of water, at each and every temperature, and errors were within $\pm 0.25 \%$ range, compared to Incropera and Dewitt data [13]. 


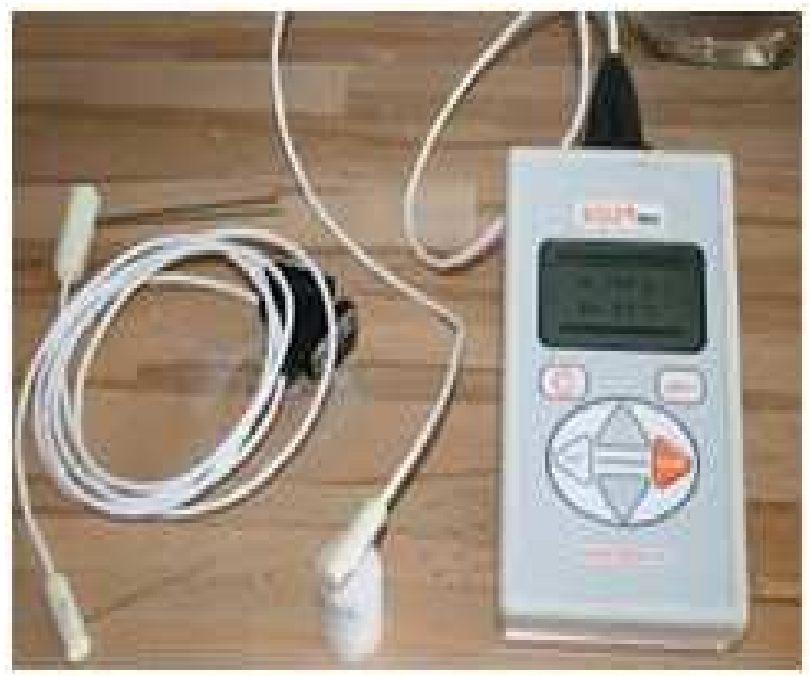

Figure 2: KD2 Pro Thermal Analyzer

\section{MESAUREMENT OF VISCOSITY}

In the past literature Viscometers and rheometers were used, to measure the viscosity of the nanofluids. In this study, digital Brookfield Viscometer (make: Ktek analytics, India.), with the spindle speed in the range of 0 to $1000 \mathrm{rpm}$, is used for measuring the viscosity of the nanofluid, for different particle loading and at different temperatures, and is shown in Figure 2. Before starting the measurements with the nanofluid, the rheometer was calibrated with the known viscosity of water, at each and every temperature, and errors were within $\pm 0.5 \%$, compared to Incropera and Dewitt data [13]. Water + EG based alumina nanofluids are tested at shear rates, from 200 to $500 \mathrm{~s}^{-1}$.

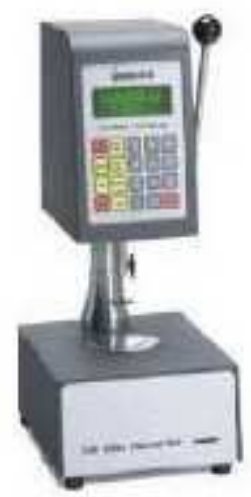

Figure 3: Brookfield Viscometer Apparatus

\section{RESULTS}

\section{Thermal Conductivity}

Experiments were conducted to determine the thermal conductivity of water + EG based alumina nanofluid, for various nanoparticle, loading from 0.2 to $1.6 \mathrm{Vol} \%$ and at different temperatures, from $30{ }^{\circ} \mathrm{C}$ to $70{ }^{\circ} \mathrm{C}$. It is observed that, the thermal conductivity is increased with the addition of alumina nanoparticles, and the thermal conductivity improvement is increased with the increase in nanoparticle loading. The maximum enhancement is observed at $11.37 \%$, for water+EG based alumina nanofluid. 
Table 3: Experimental and Predicted Effective Thermal Conductivity for Various Particle Loading and Temperatures

\begin{tabular}{|c|c|c|c|c|c|}
\hline Vol. Fraction $\Phi$ & Temperature $\left({ }^{\circ} \mathrm{C}\right)$ & $\Phi^{2}$ & Experimental $K_{n f} / K_{b f}$ & Predicted $K_{n f} / K_{b f}$ & Error \% \\
\hline 0.2 & 30 & 0.04 & 1.015697138 & 1.010342 & 0.527238 \\
\hline 0.2 & 40 & 0.04 & 1.016117414 & 1.013582 & 0.24952 \\
\hline 0.2 & 50 & 0.04 & 1.013245033 & 1.016822 & -0.35302 \\
\hline 0.2 & 60 & 0.04 & 1.015411406 & 1.020062 & -0.458 \\
\hline 0.2 & 70 & 0.04 & 1.020180335 & 1.023302 & -0.30599 \\
\hline 0.4 & 30 & 0.16 & 1.028070175 & 1.023248 & 0.469051 \\
\hline 0.4 & 40 & 0.16 & 1.028273006 & 1.026488 & 0.173593 \\
\hline 0.4 & 50 & 0.16 & 1.02781457 & 1.029728 & -0.18616 \\
\hline 0.4 & 60 & 0.16 & 1.030909882 & 1.032968 & -0.19964 \\
\hline 0.4 & 70 & 0.16 & 1.033920137 & 1.036208 & -0.22128 \\
\hline 0.8 & 30 & 0.64 & 1.049307479 & 1.049912 & -0.05761 \\
\hline 0.8 & 40 & 0.64 & 1.048082118 & 1.053152 & -0.48373 \\
\hline 0.8 & 50 & 0.64 & 1.053421634 & 1.056392 & -0.28197 \\
\hline 0.8 & 60 & 0.64 & 1.058772312 & 1.059632 & -0.0812 \\
\hline 0.8 & 70 & 0.64 & 1.068699012 & 1.062872 & 0.545244 \\
\hline 1 & 30 & 1 & 1.06278855 & 1.06367 & -0.08294 \\
\hline 1 & 40 & 1 & 1.060687916 & 1.06691 & -0.58661 \\
\hline 1 & 50 & 1 & 1.067549669 & 1.07015 & -0.24358 \\
\hline 1 & 60 & 1 & 1.074793209 & 1.07339 & 0.130556 \\
\hline 1 & 70 & 1 & 1.082868184 & 1.07663 & 0.57608 \\
\hline 1.6 & 30 & 2.25 & 1.100184672 & 1.0993075 & 0.07973 \\
\hline 1.6 & 40 & 2.25 & 1.101206555 & 1.1025475 & -0.12177 \\
\hline 1.6 & 50 & 2.25 & 1.101986755 & 1.1057875 & -0.3449 \\
\hline 1.6 & 60 & 2.25 & 1.109621245 & 1.1090275 & 0.053509 \\
\hline 1.6 & 70 & 2.25 & 1.113782739 & 1.1122675 & 0.136044 \\
\hline
\end{tabular}

From the regression analysis, the thermal conductivity correlation is developed, based on the parameters like Volume fraction, Temperature, Volume fraction * Volume fraction as

Nanofluid Thermal conductivity

$$
K_{n f}=K_{b f}\left(0.988+0.0624 \phi+0.00355 \phi^{2}+0.000324 T\right)
$$

Table 3, shows the experimental and predicted values of thermal conductivity of water + EG based alumina nanofluid, for various nanoparticle loading from 0.2 to $1.6 \mathrm{Vol} \%$, and at temperatures of $30{ }^{\circ} \mathrm{C}$ to $70{ }^{\circ} \mathrm{C}$. It is identified that, the maximum percentage error is $-0.58 \%$. Figure 2 , shows the comparison between experimental and predictive effective thermal conductivities. 


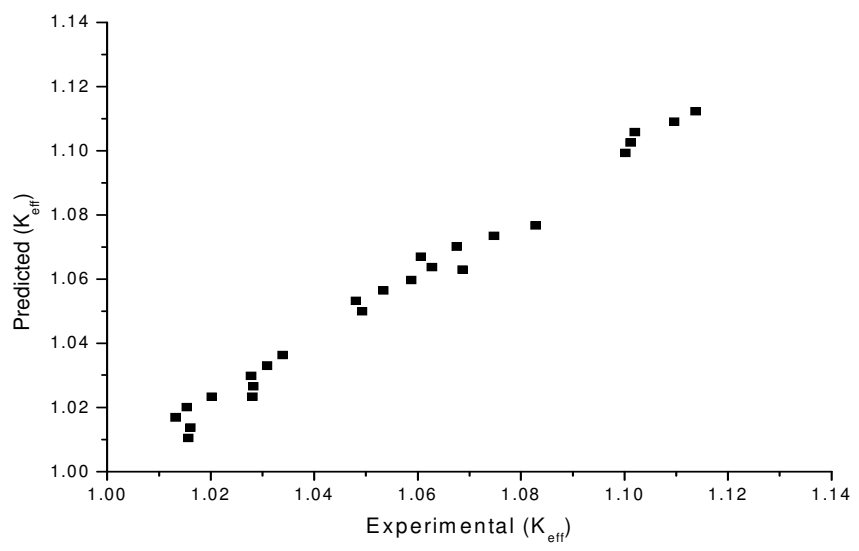

Figure 4: Comparison of Experimental and Predictive Effective Thermal Conductivity of Water + EG Based Alumina Nanofluid

\section{VISCOSITY}

Experiments were conducted to determine the viscosity of water + EG based, alumina nanofluid for various nanoparticle loading, from 0.2 to $1.6 \mathrm{Vol} \%$ and at different temperatures, from $30{ }^{\circ} \mathrm{C}$ to $70{ }^{\circ} \mathrm{C}$. It is observed that, the viscosity is increased with the addition of alumina nanoparticles, and the viscosity improvement is increased with the increase in nanoparticle loading. The maximum enhancement is observed at $10.36 \%$, for water+EG based alumina nanofluid.

From the regression analysis, the viscosity correlation is developed, based on the parameters like Volume fraction, Temperature, Volume fraction * Volume fraction as

Nanofluid viscosity

$$
\mu_{n f}=\mu_{b f}\left(0.994+0.0457 \phi+0.0145 \phi^{2}-0.0000001 T\right)
$$

Table 4: Experimental and Predicted Effective Viscosity for Various Particle Loading and Temperatures

\begin{tabular}{|c|c|c|c|c|c|}
\hline Vol. Fraction $\boldsymbol{\Phi}$ & Temperature $\left.\mathbf{~}^{\mathbf{0}} \mathbf{C}\right)$ & $\boldsymbol{\Phi}^{\mathbf{2}}$ & Experimental $\boldsymbol{\mu}_{\mathbf{n f}} / \boldsymbol{\mu}_{\mathbf{b f}}$ & Predicted $\boldsymbol{\mu}_{\text {nf }} / \boldsymbol{\mu}_{\mathbf{b f}}$ & Error \% \\
\hline 0.2 & 30 & 0.04 & 1.005 & 1.00372 & 0.127363 \\
\hline 0.2 & 40 & 0.04 & 1.005 & 1.00372 & 0.127363 \\
\hline 0.2 & 50 & 0.04 & 1.005 & 1.00372 & 0.127363 \\
\hline 0.2 & 60 & 0.04 & 1.005 & 1.00372 & 0.127363 \\
\hline 0.2 & 70 & 0.04 & 1.005 & 1.00372 & 0.127363 \\
\hline 0.4 & 30 & 0.16 & 1.01505 & 1.0146 & 0.044333 \\
\hline 0.4 & 40 & 0.16 & 1.01505 & 1.0146 & 0.044333 \\
\hline 0.4 & 50 & 0.16 & 1.01505 & 1.0146 & 0.044333 \\
\hline 0.4 & 60 & 0.16 & 1.01505 & 1.0146 & 0.044333 \\
\hline 0.4 & 70 & 0.16 & 1.01505 & 1.0146 & 0.044333 \\
\hline 0.8 & 30 & 0.64 & 1.033535 & 1.03984 & -0.61003 \\
\hline 0.8 & 40 & 0.64 & 1.033535 & 1.03984 & -0.61003 \\
\hline 0.8 & 50 & 0.64 & 1.033535 & 1.03984 & -0.61003 \\
\hline 0.8 & 60 & 0.64 & 1.033535 & 1.03984 & -0.61003 \\
\hline 0.8 & 70 & 0.64 & 1.033535 & 1.03984 & -0.61003 \\
\hline 1 & 30 & 1 & 1.061235 & 1.0542 & 0.662907 \\
\hline 1 & 40 & 1 & 1.061235 & 1.0542 & 0.662907 \\
\hline 1 & 50 & 1 & 1.061235 & 1.0542 & 0.662907 \\
\hline
\end{tabular}




\begin{tabular}{|c|c|c|c|c|c|}
\hline 1 & 60 & 1 & 1.061235 & 1.0542 & 0.662907 \\
\hline \multicolumn{7}{|c|}{ Table 4 : Contd., } \\
\hline 1 & 70 & 1 & 1.061235 & 1.0542 & 0.662907 \\
\hline 1.6 & 30 & 2.56 & 1.103684 & 1.10424 & -0.05038 \\
\hline 1.6 & 40 & 2.56 & 1.103684 & 1.10424 & -0.05038 \\
\hline 1.6 & 50 & 2.56 & 1.103684 & 1.10424 & -0.05038 \\
\hline 1.6 & 60 & 2.56 & 1.103684 & 1.10424 & -0.05038 \\
\hline 1.6 & 70 & 2.56 & 1.103684 & 1.10424 & -0.05038 \\
\hline
\end{tabular}

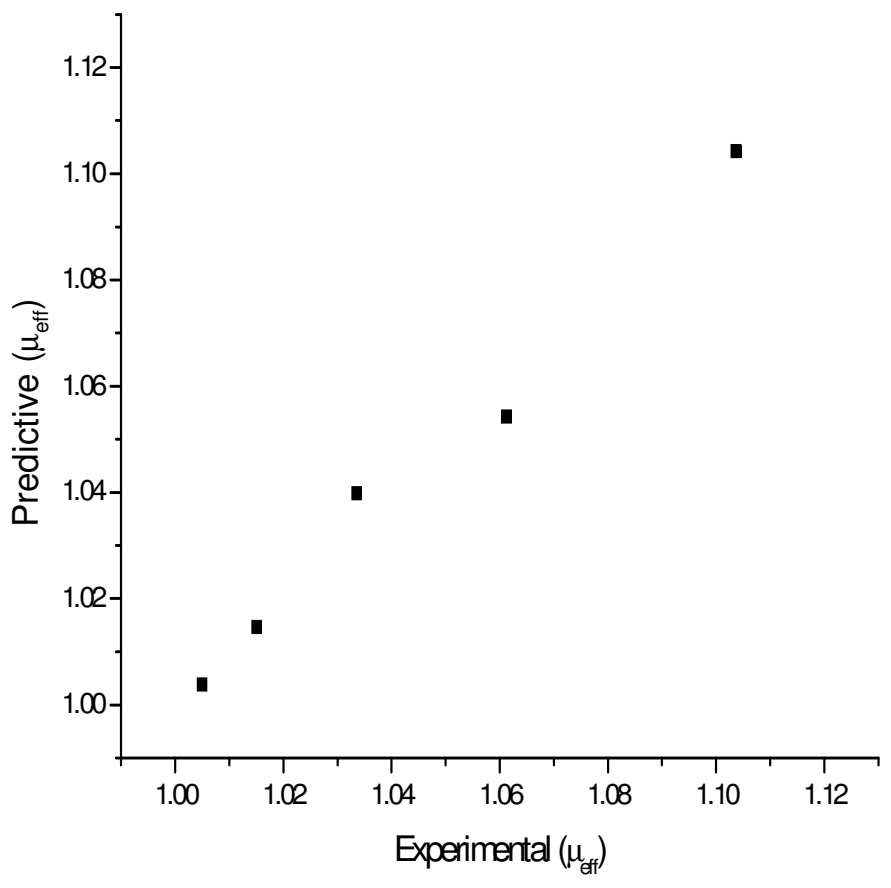

Figure 5: Comparison of Experimental and Predictive Effective Viscosity of Water + EG Based Alumina Nanofluid

Table 4, shows the experimental and predicted values of viscosity of water + EG, based alumina nanofluid, for various nanoparticle loading from 0.2 to $1.6 \mathrm{Vol} \%$, and at temperatures of $30{ }^{\circ} \mathrm{C}$ to $70{ }^{\circ} \mathrm{C}$. It is identified that, the maximum percentage error is $-0.66 \%$. Figure 5 , shows the comparison between experimental and predictive effective viscosities.

\section{CONCLUSIONS}

Thermo- Physical properties of water $+\mathrm{EG}$ based $\mathrm{Al}_{2} \mathrm{O}_{3}$ nanofluid, like thermal conductivity and dynamic viscosity were measured, for different volume concentrations of nanoparticles, from $0 \mathrm{Vol} \%$ to $1.6 \mathrm{Vol} \%$. It is observed that, the maximum augmentation occured in the thermal conductivity is $11.37 \%$, at $1.6 \mathrm{Vol} \%$ for water $+\mathrm{EG}$ based $\mathrm{Al}_{2} \mathrm{O}_{3}$ nanofluids. It is also observed that, dynamic viscosity is increased by $10.36 \%$, by $1.6 \mathrm{Vol} \%$, for Water $+\mathrm{EG} / \mathrm{Al}_{2} \mathrm{O}_{3}$ nanofluid, compared to water + EG blend.

Thermal conductivity and viscosity models for water $+\mathrm{EG}$ based $\mathrm{Al}_{2} \mathrm{O}_{3}$ nanofluid, are proposed as

$$
K_{n f}=K_{b f}\left(0.988+0.0624 \phi+0.00355 \phi^{2}+0.000324 T\right)
$$




$$
\mu_{n f}=\mu_{b f}\left(0.994+0.0457 \phi+0.0145 \phi^{2}-0.0000001 T\right)
$$

\section{ACKNOWLEDGEMENTS}

The authors are grateful to the management of the GMR Institute of Technology, for providing the infrastructural facilities, to carry out this research work.

\section{REFERENCES}

1. J.C. Maxwell, On Electricity and Magnetism, Oxford University Press, Oxford, 1881.

2. F.J. Wasp, Solid-Liquid Slurry Pipeline Transportation, Trans., Tech, Berlin, 1977.

3. Ravikanth S. Vajjha, Debendra K. Das, Experimental determination of thermal conductivity of three nanofluids and development of new correlations, International Journal of Heat and Mass Transfer, 2009, 52, 4675-4682.

4. M.Kh. Abdolbaqi, Nor Azwadi Che Sidik, Mohd Fadzil Abdul Rahim, Rizalman Mamat, W.H. Azmi, Mohammad Noor AfiqWitri Muhammad Yazid et.al, Experimental investigation and development of new correlation for thermal conductivity and viscosity of BioGlycol/water based $\mathrm{SiO}_{2}$ nanofluids, International Communications in Heat and Mass Transfer, 2016, 77, 5463.

5. L. Syam Sundar, Maria J. Hortiguela, Manoj K. Singh, Antonio C.M. Sousa, Thermal conductivity and viscosity of water based nanodiamond (ND) nanofluids: An experimental study, International Communications in Heat and Mass Transfer, 2016, 76, 245-255.

6. Srinivas Maripala et al., Micropolar Nanofluid Flow over a MHD Radiative Stretching Surface with Thermal Conductivity and Heat Source/Sink, International Journal of Mathematics and Computer Applications Research (IJMCAR), Volume 7, Issue 1, Jan-Feb 2017, pp. 23-34

7. Brinkman HC. The viscosity of concentrated suspensions and solutions. The Journal of Chemical Physics 1952, 20, 571-581.

8. Gherasim I, Roy G, Nguyen CT, Vo-Ngoc D, Experimental investigation of nanofluids in confined laminar radial flows, International Journal of Thermal Science, 2009, 48, 1486-1493.

9. Orozco, D. Hydrodynamic behavior of suspension of polar particles. Encyclo- Pedia Surface Colloid Science, 2005, 4, 23752396.

10. Nguyen CT, Desgranges F, Galanis N, Roy G, Mare T, Boucher S, Mintsa HA. Viscosity dataforAl ${ }_{2} \mathrm{O}_{3}$-water nanofluidhysteresis: is heat transfer enhancement using nanofluids reliable? International Journal of Thermal Science, 2008, 47, 103111.

11. Maiga SEB, Palm SM, Nguyen CT, Roy G, Galanis N. Heat transfer enhancement by using nanofluids in forced convection flows, International Journal of Heat and Fluid Flow, 2005, 26, 530-546.

12. Einstein A, Investigation on the Theory of Brownian Motion, New York, Dover, 1956.

13. Pak BC, Cho Y. Hydrodynamic and heat transfer study of dispersed fluids with submicron metal oxide particle, Experimental Heat Transfer, 1998, 11, 151-170.

14. F.P Incropera, D. P. Dewitt, Introuction to Heat Transfer, $3^{\text {rd }}$ Ed, John Wiley \& Sons Inc, NewYork, 1996.

15. Ravi Babu. S, Sambasiva Rao. G, Buoyancy induced natural convective heat transfer along a vertical cylinder under a constant heat flux, International Journal of Chemical Sciences, 14 (4), 2016, 2763-2774. 